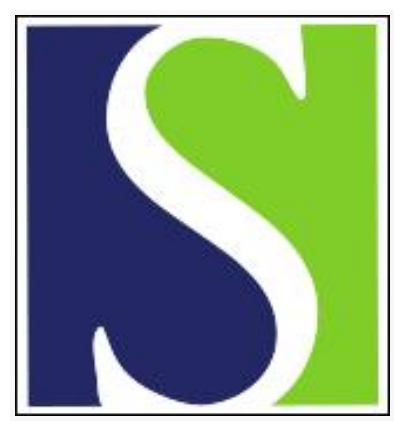

Scand J Work Environ Health 2006;32(1):12-19

https://doi.org/10.5271/sjweh.971

Issue date: 31 Feb 2006

Cardiovascular risk factors and low back pain in a long-term follow-up of industrial employees

by Leino-Arjas P, Solovieva S, Kirjonen J, Reunanen A, Riihimäki H

Affiliation: Finnish Institute of Occupational Health, Department of Epidemiology and Biostatistics, Topeliuksenkatu 41 a A, FIN-00250 Helsinki, Finland. paivi.leino-arjas@ttl.fi

The following article refers to this text: 2006;32(1):20-21

Key terms: blood pressure; cardiovascular risk factor; cholesterol; industrial employee; leisure-time physical activity; long-term follow-up; low-back pain; overweight; smoking; triglycerides

This article in PubMed: www.ncbi.nlm.nih.gov/pubmed/16539167

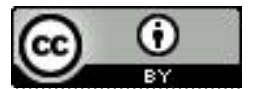




\title{
Cardiovascular risk factors and low-back pain in a long-term follow-up of industrial employees
}

\author{
by Päivi Leino-Arjas, DMedSc, ${ }^{1}$ Svetlana Solovieva, PhD, ${ }^{1}$ Juhani Kirjonen, PhD, Antti Reunanen, \\ DMedSc, ${ }^{2}$ Hilkka Riihimäki, DMedSc ${ }^{1}$
}

\begin{abstract}
Leino-Arjas P, Solovieva S, Kirjonen J, Reunanen A, Riihimäki H. Cardiovascular risk factors and low back pain in a long-term follow-up of industrial employees. Scand J Work Environ Health. 2006;32(1):12-9.
\end{abstract}

\begin{abstract}
Objectives Atherosclerosis of the lumbar vessels has been suggested as a mechanism leading to low-back pain (LBP). We studied whether seven cardiovascular disease (CVD) risk factors predict LBP.

Methods A sample ( $\mathrm{N}=902)$ stratified by gender, age, and occupational class was drawn from employees in an engineering company in 1973 and examined for body mass index (BMI), smoking, exercise, serum total cholesterol and triglyceride concentrations, systolic blood pressure (SBP), diastolic blood pressure (DBP), and LBP. By November 2000, 232 persons had died, 108 from cardiovascular causes. In 2000, 546 (81\% of the survivors) responded to a follow-up questionnaire on, for example, LBP.

Results Among the men, frequent local LBP at follow-up was predicted by high triglyceride and DBP levels and being a past smoker at baseline, adjusted for age, occupational class and frequent local LBP at baseline. In analogous models, high triglyceride and SBP levels and smoking (past and current) predicted frequent radiating LBP. An increased LBP score was predicted by a high BMI, serum total cholesterol, triglyceride, SBP and DBP levels, and smoking status at baseline. When BMI was allowed for, the associations between triglyceride level and all LBP outcomes persisted, as well as the association between SBP and frequent radiating LBP and an increased LBP score. An overall score of CVD risk factors showed a graded association with increased LBP. Among the women, a high BMI predicted frequent local and radiating LBP, and smoking at baseline predicted frequent radiating LBP and an increased LBP score.
\end{abstract}

Conclusions The study adds to the evidence supporting the atherosclerosis-LBP hypothesis particularly for men.

Key terms blood pressure, cholesterol, leisure-time physical activity, overweight, smoking, triglycerides.

Most of the population suffers from low-back pain (LBP) at some point in life, often repeatedly (1). The ensuing work disability and need for care make lowback pain one of the most costly complaints in society (2). The multifactorial etiology of low-back pain is not well described. It is assumed to involve biomechanical loading of the spine (3) and psychosocial influences (4). Tobacco smoking (5) and overweight (6), classical risk factors of cardiovascular diseases (CVD), have also long been suspected of a role in the genesis of low-back pain. In the 1958 British birth cohort, it was shown that obesity in young adult women increased the risk of a subsequent onset of low-back pain (7). Smoking and a high body mass index (BMI) were predictive of hospitalization for back disorders in a follow-up of the present study cohort of industrial employees (8).
Kauppila (9) presented the idea that atherosclerosis of the abdominal aorta and occlusion of the lumbar arteries might interfere with the nutrition of lumbar tissues and lead to low-back pain. Three-fourths of patients with long-standing nonspecific low-back pain had occluded lumbar or middle sacral arteries in magnetic resonance aortography (10). Atherosclerotic calcifications of the abdominal aorta were more frequent in computed tomographic scans of low-back pain patients than in those of controls (11). In the Framingham study, the participants with lumbar aortic calcification were somewhat more likely than others to report back pain during adult life retrospectively (12).

In the context of the atherosclerosis-low-back pain hypothesis even risk factors of atherosclerosis other than overweight and smoking can be assumed to be predictive

1 Finnish Institute of Occupational Health, Helsinki, Finland.

2 University of Jyväskylä, Jyväskylä, Finland.

3 National Public Health Institute, Helsinki, Finland.

Correspondence to: Päivi Leino-Arjas, Finnish Institute of Occupational Health, Department of Epidemiology and Biostatistics, Topeliuksenkatu 41 a A, FIN-00250 Helsinki, Finland. [E-mail: paivi.leino-arjas@ttl.fi] 
of back pain. In our research, we studied associations between seven risk factors of cardiovascular diseases and three indicators of low-back pain in a cohort comprised of employees of a large metal engineering company prospectively over the long time span of 28 years. Analyses were made regarding the associations between baseline CVD risk factor levels and the occurrence of (i) frequent local low-back pain, (ii) frequent low-back pain radiating to the lower limb(s), adjusting for the relevant baseline LBP variable, and (iii) with changes in the frequency of occurrence of any LBP symptoms combined in a sum index.

\section{Study population and methods}

\section{Study population}

A sample of 902 persons was drawn in 1973 from among those employed for at least 15 months $(\mathrm{N}=2653)$ by a large engineering company in Jyväskylä, central Finland. The sampling was made in strata by gender, age group (3 classes: born before 1926, between 19261945, in 1946 and later), and occupational class (4 classes for the men: upper white-collar and managers, clerical white-collar, skilled blue-collar, and semiskilled blue-collar; 2 classes for the women: white-collar, bluecollar) (13). Within each stratum its members were arranged in ascending order according to a score for leisure-time physical activity based on an earlier questionnaire survey made at the workplace with a very high participation rate. A systematic sample was then drawn within each stratum, securing a large variation in physical activity in the final sample.

The people who refused to participate in further examinations $(\mathrm{N}=155)$ were replaced by new persons from a reserve list (the next in order according to the score for leisure-time physical activity). During 1973-2000, 232 members of the cohort died, 108 of them due to CVD causes, according to information obtained from Statistics Finland. At the turn of 2000-2001, 546 persons (81\% of the survivors) took part in a follow-up questionnaire survey.

Ethical approval for the study was obtained from the hospital district of the Helsinki and Uusimaa Ethics Committee for Research in Occupational Health and Safety.

\section{Low-back pain}

At each survey the participants answered the question "Did you feel ache, stiffness, sensitivity to movement, numbness, or pain in the joints or muscles at the locations listed below, and how often, during the past 12 months?" The list (25 items) included the items "in the lumbosacral region", "radiation of lumbosacral pain to the right lower limb", and "radiation of lumbosacral pain to the left lower limb". Each item was scored from 0 to $3(0=$ never, $1=$ now and then, $2=$ rather often, $3=$ often or continuously). Frequent local low-back pain was defined as the response 2 or 3 to the item on local low-back pain, and frequent radiating low-back pain as the response 2 or 3 to either or both questions on radiating low-back pain.

A sum index of the three items on low-back pain (using the original categorization 0-3), labeled as the LBP score was constructed (Cronbach's alpha $=0.82$ ). The score difference (the baseline score subtracted from that at follow-up) was dichotomized as an increase of at least 3 points as the index category. This cut-off point roughly coincided with the upper tertile of the score difference distribution in the whole sample.

\section{Cardiovascular risk factors}

BMI $\left(\mathrm{kg} / \mathrm{m}^{2}\right)$ was based on self-reported height and measured weight.

Leisure-time physical activity was assessed using a two-phase questionnaire and interview method described elsewhere (14). By multiplying the number of hours spent on different activities (covering sport and exercise, housework, and commuting to work) by an intensity coefficient based on the literature and the intensity (low, moderate, high) reported by the participant, an index of leisure-time physical activity was obtained.

Standard measurements of systolic and diastolic blood pressure from the right arm with the participant in a sitting position were made by a nurse trained for this purpose, by indirect auscultation using a calibrated manometer with a $14 \times 40 \mathrm{~cm}$ cuff.

At baseline, the concentrations of total cholesterol and triglycerides in the serum after a 12-hour fast were measured and analyzed at a regional laboratory of the Finnish National Public Health Institute.

For the analyses, all of the measurements were put into tertiles. The definition of tertiles was based on gender-specific distributions.

Smoking was categorized as $0=$ never smoker, $1=$ stopped smoking, 2 = current regular smoker.

An overall risk-factor score, or the sum of trichotomized (tertiles at baseline scored as low $=1$, intermediate $=2$, high $=3$ ) BMI, serum total cholesterol, triglyceride, systolic blood pressure, diastolic blood pressure, and leisure-time physical activity (reversed), and smoking (scored as given earlier) was calculated separately for the men and women and, again, put into tertiles.

\section{Covariates}

Sociodemographic covariates were the original strata age group, gender, and occupational class, dichotomized also for the men into white-collar and blue-collar. 
Information on CVD factors and covariates was gathered at baseline.

There were some missing responses to the three LBP items and the risk factors. We wanted to use the maximum available information in each analysis, and consequently the number of participants in them varied slightly.

\section{Statistical methods}

The mean values of the risk factors were calculated for each gender. Logistic regression analysis with categorical covariates was used in the analysis of the determinants of frequent local low-back pain, frequent radiating low-back pain, and an increased LBP score, separately for the women and men. First, each CVD risk factor was entered as an independent variable together with age, occupational class, and the analogous LBP variable at baseline (frequent local low-back pain, frequent radiating low-back pain, or the baseline LBP score classified into the following four classes: 0, 1, 2-3, $\geq 4$ ). Second, the possible confounding effect of BMI on the found associations between serum lipids or blood pressure and low-back pain was assessed from the inclusion of BMI among the independent variables. Third, all seven CVD risk factors with the covariates were simultaneously entered into a multivariate model. The SPSS 12.0 statistical software package (SPSS Inc, Chicago, IL, USA) was used.

\section{Results}

The mean values of the continuous CVD risk factor variables at baseline are presented in table 1. Altogether $23 \%$ of the women and $34 \%$ of the men were regular smokers. At baseline, $21 \%$ of the women reported frequent local low-back pain, and $10 \%$ had frequent radiating low-back pain. The respective figures for the men were $20 \%$ and $9 \%$. At follow-up, the proportion of women with frequent local low-back pain was $46 \%$, and that of frequent radiating low-back pain was $31 \%$, the

Table 1. Risk factors for cardiovascular disease at baseline by gender.

\begin{tabular}{|c|c|c|c|c|}
\hline & \multicolumn{2}{|c|}{$\begin{array}{c}\text { Women } \\
(\mathrm{N}=291-293)\end{array}$} & \multicolumn{2}{|c|}{$\begin{array}{c}\text { Men } \\
(\mathrm{N}=605-609)\end{array}$} \\
\hline & Mean & SD & Mean & SD \\
\hline Body mass index $\left(\mathrm{kg} / \mathrm{m}^{2}\right)$ & 24.2 & 3.7 & 25.0 & 3.1 \\
\hline Serum cholesterol (mg/dl) & 248.0 & 51.5 & 241.3 & 47.3 \\
\hline Serum triglycerides (mg/dl) & 100.2 & 49.4 & 139.6 & 80.4 \\
\hline Systolic blood pressure & 136.2 & 22.8 & 140.7 & 18.6 \\
\hline Diastolic blood pressure & 76.0 & 13.4 & 76.5 & 14.5 \\
\hline Leisure-time physical activity & 5385.9 & 776.6 & 5168.1 & 953.1 \\
\hline
\end{tabular}

respective figures for the men being $37 \%$ and $22 \%$. An increase of at least 3 points in the LBP score was observed for $37 \%$ of the women and for $29 \%$ of the men.

The blue-collar women had a higher risk of frequent local [odds ratio (OR) 2.18, 95\% CI 1.20-3.96) and radiating (OR 3.01, 95\% CI 1.52-5.98) low-back pain at the 28-year follow-up, compared with the white-collar employees, adjusted for the relevant LBP variable at baseline and age. For the men, the occupational class blue-collar predicted frequent local (OR 1.95, 95\% CI 1.20-3.15) and radiating (OR 2.74, 95\% CI 1.52-4.93) low-back pain at follow-up, adjusted similarly. The ageadjusted odds ratio of an increased LBP score for the blue-collar women was 3.58 (95\% CI 1.84-6.97), and that for blue-collar men was 1.88 (95\% CI 1.14-3.11). The increase in the LBP score was inversely associated with the LBP score at baseline.

\section{Risk factors for cardiovascular disease in relation to low-back pain among the women}

Regular smokers and women in the highest BMI tertile at baseline had a risk that was about threefold for frequent radiating low-back pain at follow-up, when adjusted for age, occupational class, and radiating lowback pain at baseline, when compared with never-smokers or the lowest BMI tertile (table 2). Belonging to the middle or the highest BMI tertile was connected with an increased risk of frequent local low-back pain. Regular smokers at baseline had a higher risk of an increased LBP score than never-smokers.

All of the CVD risk factor variables in table 2, together with age, occupational class, and frequent radiating low-back pain at baseline were then entered into a full multivariate model of frequent radiating low-back pain at follow-up. BMI (high tertile versus low: OR 3.89, 95\% CI 1.21-12.45), smoking (regularly versus never: OR 3.25, 95\% CI 1.25-8.44), and occupational class (blue-collar versus white-collar: OR 2.36, 95\% CI 1.08-5.18) remained as predictors in addition to baseline low-back pain.

In the full model for frequent local low-back pain, BMI was the only statistically significant predictor (OR 2.74, 95\% CI 1.04-7.23) in addition to frequent local low-back pain at baseline. Occupational class (OR 3.06, 95\% CI 1.44-6.51) and smoking at baseline (OR 3.64, 95\% CI 1.31-10.13) were associated with a change in the LBP score.

\section{Risk factors of cardiovascular diseases and low-back pain among the men}

Among the men, frequent local low-back pain at followup was predicted by high triglyceride and diastolic blood pressure levels, as well as by being a past smoker at 
Table 2. Risk factors for cardiovascular at baseline in relation to local and radiating low-back pain at the 28-year follow-up and the score for increased low-back pain among the women according to a logistic regression analysis. $(0 \mathrm{R}=0 \mathrm{dds}$ ratio, $95 \% \mathrm{Cl}=95 \%$ confidence interval)

\begin{tabular}{|c|c|c|c|c|c|c|c|c|c|c|c|c|}
\hline \multirow[t]{2}{*}{ Risk factor } & \multicolumn{4}{|c|}{ Frequent local low-back pain at follow-up a } & \multicolumn{4}{|c|}{ Frequent radiating low-back pain at follow-up a } & \multicolumn{4}{|c|}{ Increase in the score for low-back pain } \\
\hline & $\begin{array}{c}\text { Total } \\
\text { number }\end{array}$ & $\begin{array}{l}\text { Number } \\
\text { of cases }\end{array}$ & $O R^{c}$ & $95 \% \mathrm{Cl}$ & $\begin{array}{c}\text { Total } \\
\text { number }\end{array}$ & $\begin{array}{l}\text { Number } \\
\text { of cases }\end{array}$ & $\mathrm{OR}^{\mathrm{c}}$ & $95 \% \mathrm{Cl}$ & $\begin{array}{c}\text { Total } \\
\text { number }\end{array}$ & $\begin{array}{l}\text { Number } \\
\text { of cases }\end{array}$ & $O R^{c}$ & $95 \% \mathrm{Cl}$ \\
\hline \multicolumn{13}{|c|}{ Leisure-time physical activity ${ }^{d}$} \\
\hline Low & 50 & 25 & 1.00 & .. & 50 & 16 & 1.00 & .. & 50 & 21 & 1.00 & .. \\
\hline Intermediate & 70 & 35 & 0.87 & $0.40-1.86$ & 67 & 27 & 1.54 & $0.67-3.53$ & 65 & 31 & 1.62 & $0.72-3.67$ \\
\hline High & 71 & 27 & 0.61 & $0.28-1.33$ & 69 & 14 & 0.61 & $0.25-1.52$ & 68 & 15 & 0.43 & $0.18-1.02$ \\
\hline \multicolumn{13}{|l|}{ Smoking } \\
\hline Never & 130 & 54 & 1.00 & .. & 128 & 31 & 1.00 & .. & 125 & 41 & 1.00 & .. \\
\hline Stopped & 26 & 13 & 1.63 & $0.63-4.20$ & 25 & 9 & 1.78 & $0.63-5.01$ & 25 & 9 & 1.25 & $0.44-3.49$ \\
\hline Current & 34 & 19 & 1.60 & $0.71-3.57$ & 32 & 17 & 2.71 & $1.13-6.49$ & 32 & 17 & 2.51 & $1.04-6.09$ \\
\hline \multicolumn{13}{|c|}{ Body mass index ${ }^{d}$} \\
\hline Low & 69 & 22 & 1.00 & .. & 68 & 13 & 1.00 & .. & 67 & 20 & 1.00 & .. \\
\hline Intermediate & 61 & 32 & 2.29 & $1.04-5.05$ & 58 & 19 & 1.86 & $0.73-4.74$ & 58 & 23 & 1.60 & $0.69-3.74$ \\
\hline High & 61 & 33 & 2.71 & $1.13-6.54$ & 60 & 25 & 3.44 & $1.25-9.47$ & 58 & 24 & 1.77 & $0.68-4.49$ \\
\hline \multicolumn{13}{|c|}{ Serum cholesterol d } \\
\hline Low & 77 & 31 & 1.00 & .. & 75 & 21 & 1.00 & .. & 73 & 24 & 1.00 & .. \\
\hline Intermediate & 61 & 27 & 1.09 & $0.52-2.28$ & 60 & 15 & 0.73 & $0.31-1.74$ & 60 & 23 & 1.16 & $0.52-2.56$ \\
\hline High & 53 & 29 & 1.64 & $0.71-3.80$ & 51 & 21 & 1.45 & $0.58-3.66$ & 50 & 20 & 1.16 & $0.47-2.88$ \\
\hline \multicolumn{13}{|c|}{ Serum triclycerides $^{d}$} \\
\hline Low & 73 & 31 & 1.00 & .. & 71 & 16 & 1.00 & .. & 69 & 23 & 1.00 & .. \\
\hline Intermediate & 64 & 30 & 1.13 & $0.55-2.32$ & 62 & 23 & 1.71 & $0.79-3.89$ & 62 & 28 & 1.30 & $0.60-2.82$ \\
\hline High & 54 & 26 & 1.14 & $0.53-2.46$ & 53 & 18 & 1.43 & $0.59-3.50$ & 52 & 16 & 0.72 & $0.31-1.67$ \\
\hline \multicolumn{13}{|c|}{ Systolic blood pressure d } \\
\hline Low & 72 & 31 & 1.00 & .. & 70 & 21 & 1.00 & .. & 68 & 26 & 1.00 & .. \\
\hline Intermediate & 65 & 30 & 1.16 & $0.57-2.39$ & 63 & 17 & 0.64 & $0.28-1.47$ & 63 & 20 & 0.60 & $0.27-1.32$ \\
\hline High & 54 & 26 & 1.12 & $0.48-2.62$ & 53 & 19 & 1.00 & $0.38-2.58$ & 52 & 21 & 0.87 & $0.34-2.19$ \\
\hline \multicolumn{13}{|c|}{ Diastolic blood pressure ${ }^{d}$} \\
\hline Low & 85 & 36 & 1.00 & .. & 82 & 26 & 1.00 & .. & 80 & 29 & 1.00 & .. \\
\hline Intermediate & 54 & 28 & 1.46 & $0.68-3.16$ & 53 & 16 & 0.60 & $0.25-1.48$ & 53 & 23 & 1.25 & $0.54-2.86$ \\
\hline High & 52 & 23 & 1.09 & $0.47-2.53$ & 51 & 15 & 0.65 & $0.24-1.72$ & 50 & 15 & 0.67 & $0.26-1.72$ \\
\hline \multicolumn{13}{|c|}{ Overall score for the cardiovascular risk factors ${ }^{e}$} \\
\hline Low & 77 & 31 & 1.00 & .. & 75 & 17 & 1.00 & .. & 73 & 23 & 1.00 & .. \\
\hline Intermediate & 69 & 28 & 1.04 & $0.51-2.11$ & 68 & 21 & 1.45 & $0.65-3.27$ & 68 & 25 & 1.22 & $0.58-2.60$ \\
\hline High & 44 & 27 & 2.61 & $0.99-6.86$ & 42 & 19 & 2.37 & $0.83-6.82$ & 41 & 19 & 1.85 & $0.67-5.06$ \\
\hline
\end{tabular}

at least rather often during the past year; the analogous variable at baseline included as a covariate.

b Index group: increase of $\geq 3$ points (upper tertile) in the sum score difference between the follow-up and baseline; the baseline score also included as a covariate.

c Adjusted for age, gender, and occupational class.

${ }^{d}$ Tertiles of the distribution among the women in the original sample.

${ }^{\mathrm{e}}$ Tertiles of the sum of the seven risk factors (trichotomized) in the table.

baseline, when adjusted for age, occupational class, and frequent local low-back pain at baseline (table 3). In models with analogous covariates, frequent radiating low-back pain was predicted by high triglycerides, intermediate diastolic blood pressure, intermediate and high systolic blood pressure, as well as past and current smoking at baseline. An increased LBP score was predicted by high BMI, serum total cholesterol, triglycerides, systolic blood pressure, and diastolic blood pressure, as well as past and current smoking at baseline, adjusted for age, occupational class, and the LBP score at baseline. The overall risk factor score showed a graded association with the LBP indicators, most clearly with increased low-back pain.

We also examined to what extent the associations of the serum lipid and blood pressure levels with LBP indicators could be due to a confounding effect by BMI. In models allowing for BMI in addition to the aforementioned covariates, the following associations persisted: baseline triglycerides predicted frequent local low-back pain (high tertile versus low: OR 1.84, 95\% CI 1.033.28) and frequent radiating low-back pain (high tertile versus low: OR 1.97, 95\% CI 1.00-3.87) at follow-up, and baseline systolic blood pressure predicted frequent radiating low-back pain at follow-up (intermediate tertile versus low: OR $2.06,95 \%$ CI $1.06-4.03$, and high tertile versus low: OR 2.14, 95\% CI 1.05-4.30). In addition, the associations of baseline triglycerides (high tertile versus low: OR 2.08, 95\% CI 1.12-3.87) and systolic blood pressure (high tertile versus low: OR 2.51, 95\% CI 1.34-4.71) with an increased LBP score were retained. 
Table 3. Risk factors for cardiovascular disease at baseline in relation to local and radiating low-back pain in the 28-year follow-up and an increased score for low-back pain among the men in a logistic regression analysis. (OR = odds ratio, 95\% $\mathrm{Cl}=95 \%$ confidence interval)

\begin{tabular}{|c|c|c|c|c|c|c|c|c|c|c|c|c|}
\hline \multirow[t]{2}{*}{ Risk factor } & \multicolumn{4}{|c|}{ Frequent local low-back pain at follow-up a } & \multicolumn{4}{|c|}{ Frequent radiating low-back pain at follow-up a } & \multicolumn{4}{|c|}{ Increase in the score for low-back pain ${ }^{b}$} \\
\hline & $\begin{array}{c}\text { Total } \\
\text { number }\end{array}$ & $\begin{array}{l}\text { Number } \\
\text { of cases }\end{array}$ & $\mathrm{OR}^{\mathrm{c}}$ & $95 \% \mathrm{Cl}$ & $\begin{array}{c}\text { Total } \\
\text { number }\end{array}$ & $\begin{array}{l}\text { Number } \\
\text { of cases }\end{array}$ & $\mathrm{OR}^{\mathrm{c}}$ & $95 \% \mathrm{Cl}$ & $\begin{array}{l}\text { Total } \\
\text { number }\end{array}$ & $\begin{array}{l}\text { Number } \\
\text { of cases }\end{array}$ & $\mathrm{OR}^{\mathrm{c}}$ & $95 \% \mathrm{Cl}$ \\
\hline \multicolumn{13}{|c|}{ Leisure-time physical activity ${ }^{d}$} \\
\hline Low & 103 & 46 & 1.00 &.$\cdot$ & 102 & 29 & 1.00 &.$\cdot$ & 100 & 30 & 1.00 &. \\
\hline Intermediate & 108 & 34 & 0.67 & $0.37-1.22$ & 106 & 17 & 0.55 & $0.27-1.11$ & 106 & 28 & 0.86 & $0.46-1.60$ \\
\hline High & 142 & 52 & 0.78 & $0.45-1.35$ & 138 & 31 & 0.81 & $0.43-1.51$ & 137 & 42 & 1.11 & $0.62-1.99$ \\
\hline \multicolumn{13}{|l|}{ Smoking } \\
\hline Never & 151 & 42 & 1.00 &.. & 149 & 19 & 1.00 & .. & 148 & 30 & 1.00 & .. \\
\hline Stopped & 106 & 50 & 2.15 & $1.23-3.76$ & 104 & 32 & 2.85 & $1.45-5.58$ & 103 & 38 & 2.42 & $1.33-4.37$ \\
\hline Current & 95 & 40 & 1.15 & $0.87-2.74$ & 92 & 26 & 2.12 & $1.06-4.24$ & 91 & 32 & 2.28 & $1.24-4.18$ \\
\hline \multicolumn{13}{|c|}{ Body mass index ${ }^{d}$} \\
\hline Low & 138 & 42 & 1.00 & .. & 134 & 21 & 1.00 & .. & 133 & 26 & 1.00 &.. \\
\hline Intermediate & 113 & 42 & 1.27 & $0.72-2.22$ & 111 & 27 & 1.94 & $0.99-3.79$ & 111 & 32 & 1.89 & $1.02-3.51$ \\
\hline High & 102 & 48 & 1.78 & $0.99-3.21$ & 101 & 29 & 2.00 & $0.99-4.08$ & 99 & 42 & 3.64 & $1.91-6.94$ \\
\hline \multicolumn{13}{|c|}{ Serum cholesterol d } \\
\hline Low & 148 & 47 & 1.00 & .. & 143 & 31 & 1.00 & .. & 142 & 37 & 1.00 & .. \\
\hline Intermediate & 101 & 37 & 1.30 & $0.72-2.34$ & 101 & 18 & 0.90 & $0.44-1.84$ & 99 & 20 & 0.75 & $0.39-1.44$ \\
\hline High & 104 & 48 & 1.60 & $0.88-2.89$ & 102 & 28 & 1.25 & $0.63-2.48$ & 102 & 43 & 2.04 & $1.11-3.76$ \\
\hline \multicolumn{13}{|c|}{ Serum triglycerides ${ }^{d}$} \\
\hline Low & 139 & 43 & 1.00 & .. & 136 & 24 & 1.00 &.. & 135 & 29 & 1.00 & .. \\
\hline Intermediate & 105 & 36 & 1.02 & $0.58-1.81$ & 103 & 20 & 1.25 & $0.62-2.51$ & 103 & 29 & 1.42 & $0.77-2.62$ \\
\hline High & 107 & 53 & 2.01 & $1.15-3.52$ & 105 & 33 & 2.19 & $1.14-4.19$ & 103 & 42 & 2.65 & $1.46-4.81$ \\
\hline \multicolumn{13}{|c|}{ Systolic blood pressured } \\
\hline Low & 136 & 43 & 1.00 & .. & 133 & 18 & 1.00 & .. & 131 & 27 & 1.00 &.. \\
\hline Intermediate & 128 & 55 & 1.62 & $0.95-2.76$ & 125 & 33 & 2.11 & $1.09-4.11$ & 125 & 36 & 1.65 & $0.92-2.97$ \\
\hline High & 89 & 34 & 1.36 & $0.75-2.47$ & 88 & 26 & 2.28 & $1.13-4.62$ & 87 & 37 & 2.76 & $1.49-5.10$ \\
\hline \multicolumn{13}{|c|}{ Diastolic blood pressure ${ }^{d}$} \\
\hline Low & 154 & 45 & 1.00 &.. & 151 & 24 & 1.00 & .. & 150 & 36 & 1.00 & .. \\
\hline Intermediate & 107 & 46 & 1.83 & $1.04-3.22$ & 106 & 29 & 2.09 & $1.07-4.08$ & 105 & 31 & 1.45 & $0.79-2.64$ \\
\hline High & 92 & 41 & 1.87 & $1.03-3.40$ & 89 & 24 & 1.94 & $0.95-3.99$ & 88 & 33 & 2.07 & $1.10-3.87$ \\
\hline \multicolumn{13}{|c|}{ Overall score for cardiovascular risk factors ${ }^{e}$} \\
\hline & 150 & 43 & 1.00 &.. & 147 & 21 & 1.00 &.$\cdot$ & 146 & 26 & 1.00 &.$\cdot$ \\
\hline Intermediate & 116 & 47 & 1.53 & $0.89-2.64$ & 112 & 24 & 1.57 & $0.79-3.12$ & 111 & 36 & 2.50 & $1.36-4.63$ \\
\hline High & 84 & 42 & 2.14 & $1.14-4.01$ & 84 & 32 & 3.63 & $1.75-7.52$ & 83 & 38 & 4.95 & $2.49-9.86$ \\
\hline
\end{tabular}

a The analogous variable at baseline included as a covariate.

b Index group: increase of $\geq 3$ points (upper tertile) in the sum score difference between the follow-up and baseline; the baseline score also included as a covariate.

${ }^{c}$ Adjusted for age, gender, and occupational class.

d Tertiles of the distribution among the men in the original sample.

e Tertiles of the sum of the seven risk factors (trichotomized) in the table.

The associations between smoking and low-back pain at follow-up or the increase in the LBP score were not materially affected by allowing for BMI.

In a full multivariate model of frequent radiating low-back pain, smoking (stopped versus never: OR 2.70, 95\% CI 1.34-5.45, regularly versus never: OR 2.15, 95\% CI 1.03-4.46) and occupational class (blue-collar versus white-collar: OR $2.53,95 \%$ CI $1.34-4.79)$ remained as predictors in addition to frequent radiating low-back pain at baseline. In a full model of frequent local low-back pain, smoking (stopped versus never: OR 2.21, 95\% CI 1.23-3.98) and blue-collar occupational class (OR 1.79, 95\% 1.07-2.99), in addition to frequent local low-back pain at baseline, remained statistically significant. The associations for BMI, systolic blood pressure, and smoking persisted in a full model for increased low-back pain (table 4).

The LBP score decreased during the follow-up among $13.6 \%$ of the men and $14.8 \%$ of the women. This decrease was not associated with the CVD risk factors in either group.

\section{Discussion}

The associations of seven CVD risk factors with lowback pain were studied prospectively in a long followup in a cohort of employees in the metal industry. We examined frequent local low-back pain and frequent 
radiating low-back pain separately at follow-up, allowing for similar pain at baseline, and an indicator of any increase in the frequency of occurrence of low-back pain, allowing also for this score at baseline. Several associations were found particularly for the men. A history of past smoking and the level of serum triglycerides at baseline were associated with all three outcomes among the men when adjusted for age and occupational class. Current smoking at baseline was predictive of frequent radiating low-back pain and an increase in the LBP score. Systolic blood pressure was associated with frequent radiating low-back pain and an increased LBP score, while the associations of diastolic blood pressure were less consistent. All of the studied risk factors, with the exception of leisure-time physical activity, were predictive of an increased frequency of low-back pain. For the women, BMI was associated with frequent local and radiating low-back pain, and smoking with the latter.

Among the limitations of our study are the questionnaire-based outcomes and the relatively small sample size, especially for the women. The cohort originally represented the healthy working population with few severe cases of any kind of morbidity. The eligibility criterion of employment by an enterprise for at least 15 months accentuated the selection toward the more healthy adult subpopulation. Motivation to participate in a half-day clinical examination was also required. This motivational basis was perhaps a reason for the high participation rate almost 28 years after the baseline. These factors, as well as the sampling strategy, limit possibilities for generalization of the results to the normal population, but they underline the significance of the studied risk factors as determinants of low-back pain.

At each examination, the occurrence of back pain was inquired about over the past 12 months. No information was available regarding the time in between, and consequently no realistic incidence measures could be constructed. The current view of low-back pain emphasizes its repetitive nature (15). Frequently occurring pain may be assumed to have more serious consequences for functioning than less frequent pain. We have previously observed that frequent or radiating low-back pain at baseline was predictive of back-related hospitalization during the 28-year follow-up among the participants of our study (16). Consequently, we focused on frequently occurring low-back pain, in addition to a change in the LBP sum score. The latter depicted any change in the three items on low-back pain and seemed like the most sensitive measure to reveal associations with the CVD risk factors among men.

In our study, radiation of low-back pain was defined as lumbosacral pain with radiation to any level between the toes and thighs, and radiation to both sides was commonly reported. There were probably few cases of true
Table 4. Full multivariate logistic regression modela of an increased score for low-back pain during the 28-year follow-up among the men. $(\mathrm{OR}=$ odds ratios, $95 \% \mathrm{Cl}=95 \%$ confidence intervals)

\begin{tabular}{|c|c|c|c|c|}
\hline \multirow{2}{*}{$\begin{array}{l}\text { Cardiovascular } \\
\text { risk factors at } \\
\text { baseline }\end{array}$} & \multicolumn{4}{|c|}{ Increase in the score for low-back pain ${ }^{b}$} \\
\hline & $\begin{array}{c}\text { Total } \\
\text { number }\end{array}$ & $\begin{array}{l}\text { Number } \\
\text { of cases }\end{array}$ & $\mathrm{OR}$ & $95 \% \mathrm{Cl}$ \\
\hline \multicolumn{5}{|c|}{ Leisure-time physical activity ${ }^{c}$} \\
\hline Low & 100 & 30 & 1.00 & .. \\
\hline Intermediate & 105 & 28 & 0.95 & $0.48-1.89$ \\
\hline High & 135 & 42 & 1.16 & $0.61-2.19$ \\
\hline \multicolumn{5}{|l|}{ Smoking } \\
\hline Never & 148 & 30 & 1.00 & .. \\
\hline Stopped & 102 & 38 & 2.11 & $1.12-3.99$ \\
\hline Current & 90 & 32 & 2.33 & $1.20-4.54$ \\
\hline \multicolumn{5}{|c|}{ Body mass index ${ }^{c}$} \\
\hline Low & 130 & 26 & 1.00 &.$\cdot$ \\
\hline Intermediate & 111 & 32 & 1.72 & $0.88-3.36$ \\
\hline High & 99 & 42 & 2.85 & $1.39-5.87$ \\
\hline \multicolumn{5}{|c|}{ Serum cholesterol ${ }^{\mathrm{C}}$} \\
\hline Low & 141 & 37 & 1.00 &.$\cdot$ \\
\hline Intermediate & 98 & 20 & 0.57 & $0.27-1.18$ \\
\hline High & 101 & 43 & 1.36 & $0.66-2.78$ \\
\hline \multicolumn{5}{|c|}{ Serum triglycerides ${ }^{c}$} \\
\hline Low & 135 & 29 & 1.00 &.. \\
\hline Intermediate & 102 & 29 & 1.00 & $0.51-1.97$ \\
\hline High & 103 & 42 & 1.43 & $0.70-2.94$ \\
\hline \multicolumn{5}{|c|}{ Systolic blood pressure ${ }^{c}$} \\
\hline Low & 130 & 27 & 1.00 & .. \\
\hline Intermediate & 124 & 36 & 1.50 & $0.80-2.84$ \\
\hline High & 86 & 37 & 2.21 & $1.09-4.49$ \\
\hline \multicolumn{5}{|c|}{ Diastolic blood pressure ${ }^{c}$} \\
\hline Low & 147 & 36 & 1.00 & .. \\
\hline Intermediate & 105 & 31 & 1.00 & $0.51-1.92$ \\
\hline High & 88 & 33 & 1.05 & $0.49-2.24$ \\
\hline
\end{tabular}

a Age group, occupational class, and the baseline score for low-back pain also included among the independent variables (not significant); -2 log likelihood 359.0.

${ }^{b}$ Index group: increase of $\geq 3$ points.

c Tertiles of the original sample.

sciatica among the participants. It has been suggested that radiating pain arises from several structures of the spine (eg, deformed facet joints, ruptured ligaments, or muscular afflictions) in addition to compression of nerve roots by protruded nucleus pulposus causing sciatica (17).

A strength of the study was that both behavioral and physiological CVD risk factors were examined. The information on these factors was available on all or most of the participants in the cohort. Associations of physiological parameters with low-back pain are not likely to suffer from reporting bias. The high response rate at follow-up also contributes to the credibility of the results. The loss to follow-up was skewed towards the older age strata.

Adjusting for BMI did not abolish the associations between the levels of triglycerides or systolic blood pressure with low-back pain. A composite score of all 
seven CVD risk factors showed a graded association with all outcomes, particularly an increased LBP sum index for the men. When the effects of all of the risk factors were studied in a full multivariate model, BMI, smoking, and systolic blood pressure emerged as independent predictors of increased low-back pain among the men.

Our results confirmed earlier reports of the importance of smoking and overweight, as well as that of bluecollar status, as indicators of an increased back pain risk. Associations of physiological CVD risk factors with back complaints have been little studied. In the Whitehall II study the role of a range of risk factors was investigated in relation to sickness absence due to back pain (18). Modest associations were found, but an association of the triglyceride level with back-related sickness absence during the follow-up among the male employees was indicated. In a cross-sectional study in Sweden, no associations between lipid concentrations and low-back pain were found in a sample from the general population (19).

According to our results, both systolic and diastolic blood pressure were relevant with respect to future lowback pain. We are not aware of previous longitudinal studies in which blood pressure levels would have been predictive of low-back pain. Among supermarket cashiers, it was observed that those with an above the median musculoskeletal pain count had higher blood pressure values than others (20). In the Whitehall II Study hypertension was not associated with sickness absence due to back pain (18). In a randomized lifestyle intervention among hypertensive workers, focusing on the treatment of hypertension, a beneficial intervention effect on disability due to neck pain was reported (21).

Physical exercise is generally considered protective of cardiovascular disorders (22), and this finding was also apparent among our participants (23). It has been difficult to show the effects of leisure-time physical activity on low-back pain (24). Physical activity during leisure time commonly and often immediately changes (to either direction) when low-back pain occurs, contrary to the other studied factors that are likely to be relatively stable over time.

There were two types of losses from our study cohort. In addition to common nonattendance, a fourth of the participants died before the last follow-up. The follow-up material represented the survivors well due to the adequate response rate.

The limited sample size of the women may have prevented associations from being detected. On the other hand, considerable selection out of the original cohort of participants with cardiovascular manifestations of atherosclerosis occurred via death. This is, of course, what happens in any normal ageing population. Mortality was higher among the men than among the women.
A total of 89 deaths due to cardiovascular diseases occurred among the men and 19 among the women. It may be that this experience of the cohort made the associations between the CVD risk factors and low-back pain better visible for the men. The relative significance of various etiologic factors of low-back pain may also differ between women and men.

Overall, the results are in accordance with the hypothesis that the atherosclerosis process may lead to low-back pain. While this may be the most plausible explanation for our findings, it is also possible that CVD, CVD risk factors, and low-back pain would be linked more directly via inflammatory mechanisms. It has been reported that overweight, smoking, serum lipids, and blood pressure correlate with the level of Creactive protein, a marker of low-grade systemic inflammation $(25,26)$. Smoking seems to increase its concentration permanently (27). In addition to atherosclerosis (28), even disc degeneration (29) and low-back pain (30, 31) may be connected with inflammation.

Obviously, there can be effects on back pain through other mechanisms as well [eg, obesity increases the mechanical load on the spine and nicotine may be toxic for disc cells (32)]. It is also conceivable that some constitutional (33) or pain regulatory (34) mechanisms would contribute to the associations.

Our findings add to the evidence on the importance of smoking and overweight in relation to low-back pain. They also provide new information on the associations between physiological CVD risk factors and low-back pain. If confirmed in other studies, these findings will have implications with respect to attempts at preventing low-back pain at the workplace and generally in the population. Future studies will hopefully also shed more light on the mechanisms of the relationships.

\section{Acknowledgments}

Research grants for the collection of the data were obtained from the Academy of Finland (project 70139) and the Ministry of Education, Finland (188/722/2000 and 146/722/2001).

\section{References}

1. Walker BF. The prevalence of low back pain: a systematic review of the literature from 1966 to 1998. J Spinal Disord. 2000;13:205-17.

2. Druss BG, Marcus SG, Olfson M, Pincus HA. The most expensive medical conditions in America. Health Aff (Millwood). 2002;21:105-11.

3. Keyserling WM. Workplace risk factors and occupational 
musculoskeletal disorders, Part 1: a review of biomechanical and psychophysical research on risk factors associated with low-back pain. AIHA J. 2000;61:39-50.

4. Hoogendoorn WE, van Poppel MNM, Bongers PM, Koes BW, Bouter LM. Systematic review of psychosocial factors at work and private life as risk factors for back pain. Spine. 2000;25:2114-25.

5. Goldberg MS, Scott SC, Mayo NE. A review of the association between cigarette smoking and the development of nonspecific back pain and related outcomes. Spine. 2000;25:9951014.

6. Leboeuf-Yde C. Body weight and low back pain: a systematic literature review of 56 journal articles reporting on 65 epidemiologic studies. Spine. 2000;25:226-37.

7. Lake JK, Power C, Cole TJ. Back pain and obesity in the 1958 British birth cohort. cause or effect? J Clin Epidemiol. 2000;53:245-50.

8. Kaila-Kangas L, Leino-Arjas P, Riihimäki H, Luukkonen R, Kirjonen J. Smoking and overweight as predictors of hospitalization for back disorders. Spine. 2003;28:1860-8.

9. Kauppila LI. Can low-back pain be due to lumbar-artery disease? Lancet. 1995;346:888-889.

10. Kauppila LI, Mikkonen R, Mankinen P, Pelto-Vasenius K, Mäenpää I. MR aortography and serum cholesterol levels in patients with long-term nonspecific lower back pain. Spine. 2004;29:2147-2152.

11. Kurunlahti M, Tervonen O, Vanharanta H, Ilkko E, Suramo I. Association of atherosclerosis with low back pain and the degree of disc degeneration. Spine. 1999;24:2080-2084.

12. Kauppila LI, McAlindon T, Evans S, Wilson PW, Kiel D, Felson DT. Disc degeneration/back pain and calcification of the abdominal aorta. A 25-year follow-up study in Framingham. Spine. 1997;22:1642-1647.

13. METELI. Terveystutkimus: otanta, menetelmät ja toteuttaminen [Health examination: sampling, methods and implementation (in Finnish with English summary)]. Jyväskylä (Finland): Research Institute of Physical Culture and Health; 1975. Reports of the Research Institute of Physical Culture and Health no 9.

14. Leino P. Does leisure-time physical activity prevent low back disorders? a prospective study of metal industry employees. Spine. 1993;18:863-71.

15. Pengel L, Herbert R, Maher C, Refsauge K. Acute low back pain: systematic review of its prognosis. BMJ. 2003;327:3237.

16. Kääriä S, Kaila-Kangas L, Kirjonen J, Riihimäki H, Luukkonen R, Leino-Arjas P. Low back pain, work absenteeism, chronic back disorders, and clinical findings in the low back as predictors of hospitalization due to low back disorders: a 28-year follow-up of industrial employees. Spine. 2005; 30:1211-8.

17. Jinkins JR. Acquired degenerative changes of the intervertebral segments at and suprajacent to the lumbosacral junction: a radioanatomic analysis of the nondiscal structures of the spinal column and perispinal soft tissues. Eur J Radiol. 2004;50:134-58.

18. Hemingway H, Shipley M, Stansfeld S, Shannon H, Frank J, Brunner E, et al. Are risk factors for atherothrombotic disease associated with back pain sickness absence? the Whitehall II Study. J Epidemiol Community Health. 1999;53:197-203.

19. Welin L, Larsson B, Svardsudd K, Tibblin G. Serum lipids, lipoproteins and musculoskeletal disorders among 50- and 60- year old men: an epidemiologic study. Scand J Rheumatol. 1978;7:7-12.

20. Lundberg U, Dohns IE, Melin B, Sandsjö L, Palmerud G, Kadefors R, et al. Psychophysiological stress responses, muscle tension, and neck and shoulder pain among supermarket cashiers. J Occup Health Psychol. 1999;4:245-55.

21. Mattila R, Malmivaara A, Kastarinen M, Kivelä S-L, Nissinen A. Effects of lifestyle intervention on neck, shoulder, elbow and wrist symptoms. Scand J Work Environ Health. 2004;30(2):191-8.

22. Thompson PD, Buchner D, Pina IL, Balady GJ, Williams MA, Marcus BH, et al. Exercise and physical activity in the prevention and treatment of atherosclerotic cardiovascular disease: a statement from the Council on Clinical Cardiology (Subcommittee on Exercise, Rehabilitation, and Prevention) and the Council on Nutrition, Physical Activity, and Metabolism (Subcommittee on Physical Activity). Circulation. 2003;107:3109-16.

23. Kivimäki M, Leino-Arjas $\mathrm{P}$, Luukkonen R, Riihimäki $\mathrm{H}$, Vahtera J, Kirjonen J. Work stress and risk of cardiovascular mortality: prospective cohort study of industrial employees. BMJ. 2002;325:857.

24. Hildebrandt VH, Bongers PM, Dul J, van Dijk FJ, Kemper HC. The relationship between leisure time physical activities and musculoskeletal symptoms and disability in worker populations. Int Arch Occup Environ Health. 2000;73(8):507-18.

25. Rohde LEP, Hennekens CH, Ridker PM. Survey of C-reactive protein and cardiovascular risk factors in apparently healthy men. Am J Cardiol. 1999;84:1018-22.

26. Ambrose JA, Barua RS. The pathophysiology of cigarette smoking and cardiovascular disease: un update. J Am Coll Cardiol. 2004;43:1731-7.

27. Tracy RP, Psaty BM, Macy E, Bovill EG, Cushman M, Cornell ES, et al. Lifetime smoking exposure affects the association of C-reactive protein with cardiovascular disease risk factors and subclinical disease in healthy elderly subjects. Arterioscler Thromb Vasc Biol. 1997; 17:2167-76.

28. Libby P, Ridker PM, Maseri A. Inflammation and atherosclerosis. Circulation. 2002;105:1135-43.

29. Takahashi H, Suguro T, Okazima Y, Motegi M, Okada Y, Kakiuchi T. Inflammatory cytokines in the herniated disc of the lumbar spine. Spine. 1996;21:218-24.

30. Solovieva S, Leino-Arjas P, Saarela J, Luoma K, Raininko R, Riihimäki H. Possible association of interleukin 1 gene locus polymorphisms with low back pain. Pain. 2004;109:8-19.

31. Watkins LR, Maier SF. Beyond neurons: evidence that immune and glial cells contribute to pathological pain states. Physiol Rev. 2002;82:981-1011.

32. Iwahashi M, Matsuzaki H, Tokuhashi Y, Wakabayashi K, Uematsu Y. Mechanism of intervertebral disc degeneration caused by nicotine in rabbits to explicate intervertebral disc disorders caused by smoking. Spine. 2002;27:1396-401.

33. Uiterwaal CS, Grobbee DE, Sakkers RJ, Helders PJ, Bank RA, Engelbert RH. A relation between blood pressure and stiffness of joints and skin. Epidemiology. 2003;14:223-7.

34. Bruehl S, Chung OY, Ward P, Johnson B, McCubbin JA. The relationship between resting blood pressure and acute pain sensitivity in healthy normotensives and chronic back pain sufferers: the effects of opioid blockage. Pain. 2002;100:191201

Received for publication: 17 March 2005 